\title{
EFFECTIVENESS OF USING POLYURETHANE FOAM TO REDUCE HEAT LOSS IN THE PREMISES FOR BREEDING
}

\author{
ЭФФЕКТИВНОСТЬ ИСПОЛЬЗОВАНИЯ ПЕНОПОЛИУРЕТАНА С ЦЕЛЬЮ \\ УМЕНЬШЕНИЯ ПОТЕРЬ ТЕПЛА В ПОМЕЩЕНИЯХ ДЛЯ БЫЧКОВ
}

\author{
Medvedev A.Y., Researcher \\ Медведев А.Ю., научный сотрудник \\ E-mail: krollon@rambler.ru
}

\author{
Lugansk National Agrarian University, Lugansk, Ukraine \\ Луганский национальный аграрный университет, Луганск, Украина
}

\begin{abstract}
It is proved that the use of polyurethane foam insulation for the purpose of walling premises for breeding allows them to halve the deficit of heat in winter. Because of this more efficient use of feed, increases the intensity and the level of growth of young comprehensive energy transformation process in the energy of live weight gain of cattle while increasing the profitability of its cultivation for meat.
\end{abstract}

\section{АННОТАЦИЯ}

Доказано, что использование пенополиуретана с целью утепления ограждающих конструкций помещений для бычков позволяет вдвое уменьшить в них дефицит тепла в зимний период года. Вследствие этого эффеекивнее используются корма, повышается интенсивность роста молодняка и уровень трансформации совокупной энергии технологического процесса в энергию прироста живой массы скота при одновременном росте рентабельности его выращивания на мясо.

\section{KEY WORDS}

Bulls; Premises; Deficit of heat; Polyurethane; Winter; Intensity of growth.

КЛЮЧЕВЫЕ СЛОВА

Бычки; Помещения; Дефицит тепла; Пенополиуретан; Зимний период; Интенсивность роста.

В условиях интенсивной технологии производства говядины при круглогодичном использовании консервированных кормов из хранилищ большое значение имеет достижение высокого уровня продуктивного использования их сухого вещества и обменной энергии [1].

Вместе с тем, при низкой температуре воздуха значительную часть энергии кормов организм животного расходует на поддержание температуры тела. Уменьшение температуры воздуха ниже 8-10 ${ }^{\circ} \mathrm{C}$ для бычков обосновывает повышение интенсивности обмена веществ на 2-3 \% (на каждый градус снижения), что увеличивает затраты корма на $15-50$ \% и более, а интенсивность роста животных снижает на $15-30 \%$ [2].

Таким образом, при разработке современной технологии откорма скота необходимо обратить внимание на фрактор низких температур в помещениях зимой, поскольку в сегодняшних хозяйственных условиях потери прироста живой массы бычков и значительные непродуктивные затраты кормов недопустимы [3].

Расходная часть теплового баланса животноводческого помещения состоит из затрат тепла на обогрев вентиляционного воздуха (65-70 \%), потерь тепла через ограждающие конструкции (32-24 \%) и потерь при испарении влаги с различных поверхностей помещения (3-6 \%)[4].

В своих предыдущих исследованиях мы доказали, что сокращение затрат тепла на обогрев объема вентиляции помещения при его уменьшении не является 
эфрфективным из-за ухудшения параметров микроклимата и снижения интенсивности роста животных под влиянием этого фактора.

Таким образом, периодическое использование дополнительных источников тепла (например, теплогенераторов) все равно является необходимым для предотвращения технологического кризиса в животноводческих помещениях.

В данном направлении имеет смысл работа в отношении снижения потерь тепла через огражда-ющие конструкции путем использования теплоизоляционных материалов. Одним из таких материалов является пенополиуретан, коэфффициент теплопередачи которого, при напылении на конструкции помещения, составляет лишь $0,02 \mathrm{BT} / \mathrm{M} \cdot \mathrm{K}[5,6]$.

Исходя из этого, была поставлена цель исследований - определить эфрективность использования пенополиуретана в помещениях для бычков с целью сокращения дефицита тепла в зимний период.

\section{МАТЕРИАЛЫ И МЕТОДЫ ИССЛЕДОВАНИЙ}

Для решения поставленных вопросов был проведен научно-хозяйственный опыт по схеме, пред-ставленной в таблице 1.

Таблица 1 - Схема опыта

\begin{tabular}{|c|c|c|}
\hline Группа & Объект исследований & Способ уменьшения дефицита тепла в помещении \\
\hline I & $\begin{array}{c}\text { Бычки } \\
\text { Симментальской } \\
\text { породы } \\
\text { при содержании }\end{array}$ & Периодический подогрев воздуха теплогенератором \\
\hline II & $\begin{array}{c}\text { на глубокой } \\
\text { подстилке в зимний } \\
\text { период } \\
\text { с 6- до 12- месячного } \\
\text { возраста }\end{array}$ & $\begin{array}{c}\text { Периодический подогрев воздуха теплогенератором + утепление стен, } \\
\text { потолка и ворот пенополиуретаном }(0,06 \text { м) }\end{array}$ \\
\hline
\end{tabular}

Кроме 15 голов подопытного молодняка, в каждом из помещений содержали еще по 185 бычков такого же возраста и живой массы. Компенсацию дефицита тепла в них периодически проводили с помощью теплогенератора.

В течение опытного периода животным скармливали одинаковые рационы (сено злаково-бобовое, силос кукурузный, патока кормовая, комбикорма), рассчитанные на 900-1000 г прироста живой массы молодняка в сутки. Питательность рационов достигала 6,9-7,9 кормовых единиц. Запланированные затраты кормов за опытный период для бычков всех групп составляли 1350-1355 кормовых единиц, а содержание обменной энергии в 1 кг сухого вещества кормов - 10,5-11,2 МДж [7].

Расчетное решение температурно-влажностного режима помещений разрабатывали для интенсивного выращивания технологической группы бычков симментальской породы комбинированного направления продуктивности, в количестве 200 голов, до 300-330 кг в возрасте 12 месяцев. При этом считали, что в октябре живая масса бычков равнялась 180-190 кг, в ноябре - 200-220 кг, в декабре - 230-250 кг, в январе - 260-280 кг, в фреврале - 270-290 кг, а в марте - 300-330 кг.

\section{РЕЗУЛЬТАТЫ И ИХ ОБСУЖДЕНИЕ}

Определение теплопотерь через ограждающие конструкции помещений для бычков, с учетом снижения коэффрициента их теплопередачи после напыления пенополиуретана, позволило сделать соответствующую коррекцию в динамике параметров температурно-влажностного режима.

Исходя из полученных данных, основанных на реальной динамике температур окружающей среды в Троицком районе Луганской области зимой 2011-2012 гг., было определено: 
- в октябре 2011 года поступления тепла превышало потери на 2684 ккал/час $(4,9 \%)$ и 8852 ккал/час $(11,9 \%)$, соответственно, в помещении без утепления пенополиуретаном и с его использованием (слой 0,06 м);

- в ноябре 2011 года в помещении для бычков был дефицит тепла, а использование пенополиуретана позволило уменьшить этот дефицит на 8035 ккал/час (в 2,3 раза);

- в декабре 2011 года поступления тепла превышало его потери на 12586 ккал/час $(16,9$ \%) и 19972 ккал/час (25,5 \%), как в помещении без утепления пенополиуретаном, так и при его использовании, что отвечало климатическим особенностям в регионе (рис. 1);

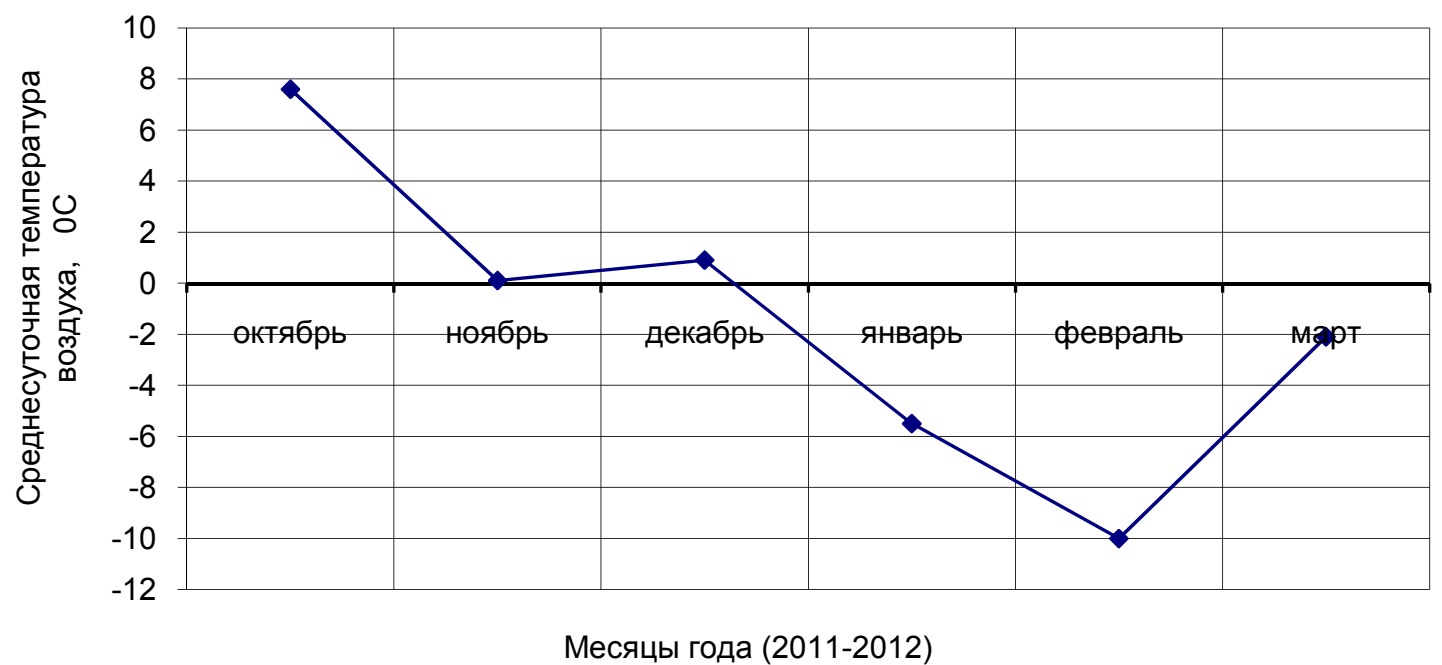

Рисунок 1 - Динамика температур атмосферного воздуха в период опытов (Троицкий район Луганской области, Украина)

- в январе 2012 года использование пенополиуретана в помещении для бычков обеспечило уменьшение дефицита тепла на 12580 ккал/час (в 2,9 раза), что, при среднесуточной температуре внешнего воздуха $-5,5^{\circ} \mathrm{C}$, является существенным фактом сбережения энергии в технологическом процессе;

- в фреврале 2012 года среднесуточные температуры воздуха в Троицком районе Луганской области были самыми низкими в течение всего года $\left(-10,0^{\circ} \mathrm{C}\right)$, однако нанесение слоя пенополиуретана на внутренние поверхности стен, потолка и ворот помещения для бычков позволило снизить дефицит тепла на 16232 ккал/час;

- в марте 2012 года, при средней суточной температуре окружающей среды $2,1^{\circ} \mathrm{C}$, напыление пенополиуретана на конструкции помещения для бычков обусловило существенное уменьшение в нем дефицита тепла на 6819 ккал/час (в 5,5 раза) и практически решило проблему негативного влияния фрактора низких температур воздуха на динамику роста молодняка.

Приведенные выше особенности кормления животных обусловили их высокую интенсивность роста (табл. 2).

При интенсивном выращивании молодняка в возрасте 7-9 месяцев, который приходился на октябрь-декабрь 2011 года, длительных снижений температуры воздуха в Троицком районе Луганской области не наблюдали (рис. 1), а существенного дефицита тепла в помещениях для бычков не было.

Таким образом, и различий по показателю живой массы скота I и II групп в возрасте 9 месяцев фрактически не определили $(3,7$ кг, 1,6 \%, p>0,05), поскольку фрактор снижения температуры на динамику роста молодняка не влиял.

В период выращивания бычков с 9- до 12- месячного возраста средние суточные температуры окружающей среды значительно уменьшились $\left(-5,5-10,0{ }^{\circ} \mathrm{C}\right)$, что обусловило появление дефицита тепла в помещениях для бычков I и II групп, 
соответственно, 19396-44845 ккал/час и 6816-28613 ккал/час. При этом периодическая работа теплогенераторов компенсировала этот дефицит тепла в обоих помещениях, поэтому действие температурного фрактора незначительно повлияло на интенсивность роста бычков, которая снизилась лишь на 2,6-6,7 \%.

Таблица 2 - Динамика живой массы бычков

\begin{tabular}{|c|c|c|}
\hline \multirow{2}{*}{ Показатель } & \multicolumn{2}{|c|}{ Группа } \\
\hline & $1(n=15)$ & il $(n=15)$ \\
\hline $\begin{array}{c}\text { Живая масса (кг), в возрасте: } \\
6 \text { мес. (октябрь } 2011 \text { г.) }\end{array}$ & $159,4 \pm 2,7$ & $161,1 \pm 2,3$ \\
\hline 9 мес. (декабрь 2011 г.) & $239,1 \pm 3,9$ & $242,8 \pm 4,1$ \\
\hline 12 мес. (март 2012 г.) & $314,6 \pm 6,4$ & $323,3 \pm 7,5$ \\
\hline $\begin{array}{c}\text { Среднесуточные приросты (г) } \\
\text { за период: } 7-9 \text { мес. }\end{array}$ & 876 & 898 \\
\hline $10-12 \mathrm{mec}$ & 821 & 875 \\
\hline $7-12$ mec & 848 & 886 \\
\hline Абсолютные приросты живой массы бычков, кГ & 155,2 & 162,2 \\
\hline $\begin{array}{c}\text { Затраты кормов на } 1 \text { кг прироста: } \\
\text { обменной энергии, МДж }\end{array}$ & 100,2 & 95,9 \\
\hline сухого вещества, кг & 9,3 & 8,9 \\
\hline кормовых единиц & 8,7 & 8,4 \\
\hline
\end{tabular}

В то же время, напыление слоя пенополиуретана на стены, потолок и двери внутри помещения для животных II группы, за счет оптимизации ряда технологических фракторов, обеспечило более высокий коэффрициент использования бычками обменной энергии кормов и увеличение приростов их живой массы за опытный период на 7,0 кг $(4,5 \%)$. Затраты кормов на 1 кг прироста живой массы бычков II группы были меньшими, в частности: обменной энергии - на 4,3 МДж (4,5\%), сухого вещества - на 0,4 кг (4,5\%), а кормовых единиц - на 0,3 (3,6 \%).

Уменьшение теплопередачи через конструкции помещения при напылении пенополиуретана позволило сократить в нем дефицит тепла с 8320-44845 ккал/час до 1501-28613 ккал/час (в 5,5-1,6 раза). В результате затраты топлива для теплогенератора, который периодически работал на компенсацию дефицита тепла (октябрь 2011 года - март 2012 года), уменьшились на 3378,2 кг (103,5 \%). В итоге были сокращены затраты энергии процесса (Q) на 425,3 ГДж/год/200 гол. (1,8 \%, табл. 3).

Таблица 3 - Расчет коэффициента биоэнергетической эфффективности производства говядины (на 200 гол.)

\begin{tabular}{|c|c|c|c|c|c|c|}
\hline Группа & $\begin{array}{c}\text { Q, } \\
\text { ГДж/год }\end{array}$ & $\begin{array}{c}V_{1}, \\
\text { гДж/год }\end{array}$ & $\begin{array}{c}\mathrm{V}_{2}, \\
\text { ГДж/год }\end{array}$ & $\begin{array}{c}\mathrm{V}_{3} \\
\text { ГДж/год }\end{array}$ & $\begin{array}{c}\text { КБЭ } \\
\text { основной продукции фермы, \% }\end{array}$ & $\begin{array}{c}\text { КБЭ } \\
\text { общей } \\
\text { продукции фрермы, \% }\end{array}$ \\
\hline 1 & 24497,8 & 661,7 & \multirow{2}{*}{2908,3} & \multirow{2}{*}{1061,9} & 2,70 & 18,91 \\
\hline iil & 24072,5 & 678,8 & & & 2,82 & 19,31 \\
\hline
\end{tabular}

Таблица 4 - Экономическая эфффективность производства говядины

\begin{tabular}{|c|c|c|}
\hline \multirow{2}{*}{ Показатель } & \multicolumn{2}{|c|}{ Группа } \\
\hline & 1 & II \\
\hline Себестоимость прироста живой массы бычка, грн. * & 2567,6 & 2567,6 \\
\hline Добавленная стоимость дизельного топлива, грн & 315,5 & 155,1 \\
\hline Общая себестоимость прироста, грн & 2883,1 & 2722,7 \\
\hline Прирост живой массы бычка за период опыта, кГ & 155,2 & 162,2 \\
\hline Себестоимость 1 ц прироста живой массы, грн. & 1857,7 & 1724,4 \\
\hline Цена условной реализации 1 кг живой массы, грн. & 20,0 & 20,0 \\
\hline Доход от условной реализации прироста, грн & 3104,0 & 3244,0 \\
\hline Прибыль от условной реализации прироста, грн. & 220,9 & 521,3 \\
\hline Рентабельность выращивания за период опыта, \% & 7,7 & 19,2 \\
\hline
\end{tabular}

Примечание: *в ценах 2012 года, в расчете на 1 голову. 
Использование теплогенератора в комплексе с напылением пенополиуретана на стены помещения для бычков в зимний период позволило уменьшить непродуктивные затраты кормов на компенсацию действия сниженных температур окружающей среды и увеличить прирост живой массы молодняка на 7,0 кг (4,5\%), а его энергию $\left(\mathrm{V}_{1}\right)$ - на 17,1 ГДж/год/200 гол. (2,6 \%). Это определило повышение коэффрициента трансформации энергии технологического процесса в энергию прироста живой массы бычков на 0,12\%.

Экономическая оценка результатов исследований также подтвердила эфффективность использования пенополиуретана для уменьшения потер тепла из животноводческих помещений (табл. 4).

Уменьшение времени работы теплогенератора в помещении для бычков II группы за зимний период на 88,9 часов (в 2,0 раза) позволило снизить добавленную стоимость потраченного дизельного топлива на 160,4 грн. (в расчете на 1 голову), увеличить прибыль от условной реализации прироста живой массы животного за период опыта на 300,4 грн. (в 2,4 раза), а рентабельность технологического процесса - повысить на $11,5 \%$.

\section{ЗАКЛЮЧЕНИЕ}

Нанесение пенополиуретанового слоя (0,06 м) на внутренние поверхности ограждающих конструкций помещения для бычков (стены, потолок и ворота), при одновременном использовании теплогенератора с целью компенсации дефицита тепла в зимний период, сравнительно с его эксплуатацией без дополнительной теплоизоляции, позволило снизить дефицит тепла на 8035-16232 ккал/час (в 1,6-2,9 раза) и повысить интенсивность роста скота на 4-5 \%. В результате коэфффициент биоэнергетической эффрективности технологического процесса производства говядины увеличился на 0,12 \%, а его рентабельность - на 12,2 \%.

\section{БИБЛИОГРАФИЯ}

[1] Медведєв А.Ю. Теоретичне та практичне обґрунтування енергозберігаючої технології виробництва яловичини за цілорічного використання консервованих кормів: [Монографія] / А.Ю. Медведєв, В.С. Ліннік. - Луганськ: Елтон-2, 2011. 222 [5-7] C.

[2] Мирось В.В. Производство молока и говядины в фрермерском хозяйстве / В.В. Мирось, В.Г. Василец, С.Б. Ковтун. - Ростов н/Д: Феникс, 2012. - 245 [67] с.

[3] Medvedev A. Modern technological decisions of intensive beef production in the milk cattle breeding // European Applied Sciences: modern approaches in scientific researches». - ORT Publishing: Stuttgart, Germany, 2012. - 479 [392-396] p.

[4] Кузнецов А.Ф. Практикум по зоогигиене / А.Ф. Кузнецов, А.А. Шуканов, В.И. Баланин, Н.В. Мухина и др. - М.: «Колос», 1999. - 208 с.

[5] Теплоизоляция из пенополиуретана. [Електронний ресурс]. - Режим доступа: http://termotechnology.com/product/read.

[6] Новые строительные технологии. [Електронний ресурс]. - Режим доступа: http://www.poliuretan.ru.

[7] Теорія і практика нормованої годівлі великої рогатої худоби: [Монографія]; За ред. В.М. Кандиби, І.І. Ібатулліна, В.І. Костенка. - Ж:, 2012. - 860 [446-469] с. 